\title{
IT Enhanced Project Information Management in Construction: Pathways to Improved Performance and Strategic Competitiveness
}

\author{
Rodney A. Stewart \\ School of Engineering, Griffith University, Gold Coast Campus, Queensland, Australia
}

\section{ALL CORRESPONDENCE TO:}

Dr. Rodney A. Stewart

Lecturer

School of Engineering

Griffith University Gold Coast Campus

PMB 50 Gold Coast Mail Centre QLD 9726, Australia

Telephone: $\quad(+617) 55528778$

Facsimile: (+61 7) 55528065

Email: r.stewart@griffith.edu.au 


\title{
IT Enhanced Project Information Management in Construction: Pathways to Improved Performance and Strategic Competitiveness
}

\begin{abstract}
Continuous process improvement via the strategic implementation of innovative information and communication technologies is essential for the long-term survival of construction firms. Some have successfully grasped the opportunities enabled by IT enhanced information management systems to develop new low-cost business models. However, not all proactive construction businesses have been satisfied with their IT investments, largely due to their limited ability to evaluate the degree of IT-induced valued added to operational and business performance. This article builds upon recently published work by the author, by empirically investigating the link between 'Construct IT' Balanced Scorecard (BSC) perspectives, utilizing structural equation modeling. Moreover, the validity of developed path equations for predicting IT-induced business performance and strategic competitiveness is reinforced through benchmarking studies, conducted on two large infrastructure projects constructed in Australia, where innovative web-based collaboration platforms were implemented.
\end{abstract}

Keywords: information technology, structural equation modeling, balanced scorecard, project information management 


\section{Introduction}

Innovative information and communication technologies are providing construction firms with new opportunities for enhancing communication, collaboration and information management processes [1]. However, the majority of construction business processes are still heavily based upon traditional means of communication such as face-to-face meetings and the exchange of paper documents in the form of technical drawings, specifications and site instructions. This is due to a number of historical, industrial and market forces that perpetuate the industry's culture, thus affecting the extent of IT adoption in day-to-day business processes [2].

Competitive pressures and client requirements are beginning to erode this entrenched culture, forcing construction firms to find efficiencies in existing processes, especially those pertaining to how project information is exchanged, manipulated and managed [3-6]. Moreover, the advent of partnered supply chains has strengthened relationships between project stakeholders who are beginning to jointly develop dynamic web-based collaboration tools for their mutual benefits $[7,8]$. These industry drivers will help to reduce the high levels of waste on construction projects which can often be traced back to poor coordination caused by less than optimum information handling and exchange, that is either inadequate, inaccurate, inappropriate, inconsistent, late or a combination of these [2].

In their quest for improved competitiveness and profitability, numerous construction firms have invested heavily into information and communication technologies [9]. However, many of these firms are yet to realize the proclaimed benefits of IT and are largely dissatisfied by their IT investments $[10,11]$. In some circumstances, this dissatisfaction has resulted from a lack of strategic IT planning $[12,13]$. In others, it is in part due to the difficulty in measuring operational benefits leading to some concerns about the payoff from investments in information technologies [14,15]. Generally, IT investment appraisal is more difficult than other investment decisions because IT-induced benefits are hard to identify and quantify [16]. This IT productivity paradox prompted calls for new approaches to evaluate IT-related investments [17]. In the last decade, numerous researchers have studied how IT investments should be evaluated and controlled across 
diverse industry sectors. Moreover, others have conducted extensive reviews and/or benchmarking studies of IT performance evaluation research and practice in the construction context $[15,18]$. The following section provides some background on the authors attempt to develop a robust IT performance evaluation framework for the construction sector.

\section{2. 'Construct IT’ BSC}

Over the last decade some attempts have been made to examine the strategic implementation and performance evaluation of IT in construction $[6,8,10,12,13,15,18-23]$. A comprehensive review of these frameworks and other related IT performance evaluation issues can be found in Stewart and Mohamed [15] and Love et al. [18]. To overcome limitations of existing frameworks, the author recently conducted two extensive studies to empirically develop an IT performance evaluation framework for the construction industry [15,24]. This 'Construct IT' BSC framework incorporates five robust IT-related performance measurement perspectives: (1) operational; (2) benefits; (3) user orientation; (4) strategic competitiveness; and (5) technology/system (Figure 1). These perspectives $(N=5)$ and their associated indicators $(N=25)$ were customised for the specific elements of IT and construction (see Table 1). The framework utilizes project-, tool- and process- specific IT indicators designed to evaluate the value IT adds to the process of project information management in construction.

In a subsequent study [22], the author verified the interrelationship between the 'Construct IT' BSC framework perspectives. Specifically, this study provided support for the theory that organizations that implement appropriate and reliable IT to re-engineer traditional processes, in conjunction with the necessary training and support, should achieve better performance in the operational perspective. This in turn should lead to improved performance in the strategic competitiveness perspective. All such efforts should lead to improved performance in the benefits perspective.

In an attempt to better quantify these links, this article utilized Structural Equation Modeling (SEM) to establish path directions, coefficients and associated path equations. Following this, the validity of the 
developed path model was reinforced through investigations on two mega construction projects where webbased project information management systems were implemented. An overview of the research method for the study is provided in the following section.

\section{(INSERT FIGURE 1)}

Fig. 1 'Construct IT’ BSC [15]

\section{Research method}

The research method for this project involved two key phases: (1) path model development; and (2) path model implementation. The first phase was concerned with developing a path model and associated prediction equations for evaluating the outcomes derived from implemented IT projects in construction businesses/projects. The objective of the second phase was to evaluate the IT-induced value added to the process of project information management on two mega construction projects and compare actual performance scores to those predicted by the standardised path equations developed in phase one of the research. This comparative analysis was conducted to reinforce the validity of the developed model.

\subsection{Path model development}

A questionnaire survey was selected as the most appropriate instrument for collecting the necessary data for the path model development. For the operational, benefits and strategic competitiveness perspectives the questionnaire asked respondents to rate the extent to which IT has helped a particular indicator compared to business as usual practices, on a five-point Likert scale ranging from (1) significant detriment, (2) some detriment, (3) no change, (4) some improvement, and (5) significant improvement. For the technology/system and user orientation perspectives, the questionnaire asked respondents to rate their overall level of satisfaction with a particular indicator, in the context of information management, on a five-point Likert scale ranging from (1) very low, (2) low, (3) adequate, (4) high, and (5) very high. 
Large construction contracting and project management firms were predominately targeted in the survey as they were most likely to adopt innovative IT for project information management, thus, the professionals working for these firms would be better suited to evaluating the importance of presented perspectives and indicators. The questionnaire was sent to 322 construction project professionals from these organizations. Eighty-two $(n=82)$ positive and complete returns were received representing an average response rate of $25 \%$. This data set was utilized for developing the path model described in later sections. SEM using AMOS 5.0 software was performed to determine the significant interrelationships between 'Construct IT' BSC perspectives and develop a robust path model. SEM is an effective technique for conceptualizing a theoretical model, confirming relationships between variables and gaining insight into the causal nature and strength of identified relationships [25]. SEM using AMOS or other second generation data analysis software (e.g. LISREL) are very effective tools for such analysis and have been utilized for a wide variety of social science and management applications.

\subsection{Path model implementation}

Following the development of the structural model, two case studies were undertaken, where the value IT added to the process of information management in construction was evaluated. The research method comprised of two stages. The first stage involved mapping the newly implemented IT-based processes and developing appropriate questions (IT performance indicators) across the five 'Construct IT' BSC perspectives. It should be noted that these questions were very similar to those used for the development of the path model (see Table 1). Moreover, the same measurement scale was maintained.

A representative sample of approximately five (5) per cent of the projects professional staff were selected to participate in the survey for both of these projects (Project 1: $n=14$; Project 2: $n=26$ ). These individuals worked across various sections (e.g. environmental, design, construction, client, etc.) of these mega projects so that a realistic representation of IT-induced performance improvement could be determined. 


\section{Model development: empirical analysis}

\subsection{Respondent profile}

Respondents were classified into four categories: director/operations manager (30\%), project manager/ project engineer/construction manager (53\%), IT professional (14\%) and other (3\%). The position of other includes human resources manager, or finance officer, or project administrator. The average work experience of respondents engaged in the survey is 13.4 years, with about $34 \%$ of respondents having more than 20 years of experience. The survey adopted an information-centric definition of IT and thus only these types of applications/tools were included. The survey demonstrated a high percentage of respondents utilizing a variety of IT applications and tools including: intranet; internet; e-mail; local area networks; wide area networks; web-based project management applications; video conferencing; and on-line remote networks. For a more comprehensive description of the respondents profile the reader is referred to Stewart and Mohamed [22].

\subsection{Evaluating perspectives and indicators}

The questionnaire asked respondents to rate each indicator using the two different five point scales, explained previously. The mean value and standard deviation for the twenty-five (25) indicators are detailed in Table 1. The mean values range from 2.89 for indicator UO1: the level and frequency of training provided, to 4.15 for indicator OP3: coordination and communication. The mean value for all indicators in the questionnaire is 3.71 indicating that respondents are moderately satisfied with their IT portfolio and the benefits it has generated. However, it should be noted that the spread of data, indicated by the relatively high standard deviations, illustrates that the respondents had varied experiences (both positive and negative) with the different aspects (e.g. OP, UO, etc.) of their IT portfolio. Examining the mean score for each perspective individually, the results are as follows: 
- The Operational perspective (OP) mean value is 3.95 indicating that respondents perceive that IT has provided some improvement to operational processes;

- The Benefits perspective (BE) mean value is 3.92 indicating that respondents perceive that IT has provided some improvement in realizing benefits on construction projects;

- The Strategic Competitiveness perspective (SC) mean value is 3.81 indicating that IT has provided some improvement in achieving strategic goals;

- The Technology/System perspective (TS) mean value is 3.55 indicating that respondents rated an adequate to high level of satisfaction with their IT portfolio; and

- The User Orientation perspective (UO) mean value is 3.31 indicating that respondents are only adequately satisfied with the degree to which their IT portfolio is meeting the needs of the user.

Pearson correlation analysis (Table 2), along with stepwise regression, was undertaken between framework perspectives to establish a preliminary understanding of paths and interrelationships. This analysis was a necessary precursor to the development of the path model described in the next section.

Table 1 Mean value and standard deviation for indicators [22]

(INSERT TABLE 1)

Table 2 Correlation between perspectives

(INSERT TABLE 2)

\subsection{Path model}

The path model was developed through SEM utilizing AMOS 5.0 software. This type of analysis dynamically evaluates the extent to which hypothesized relationships fit the observed data. One major limitation of the SEM method is that it requires large sample sizes; 15 observations for each item in the 
model. However, since previous studies $[15,24]$ have reduced the 25 indicators (items) to five perspectives through exploratory factor analysis, a sample of 75 observations was required $(n=82)$. On the basis of the previous work the technology/system perspective was defined as the only exogenous $(\gamma)$ perspective. The perspectives concerning user orientation, operational performance, strategic competitiveness, and benefits was taken as endogenous perspectives $(\beta)$. The causality relations considered are non-recursive. Moreover, scatter plots between the five perspectives were conducted to ensure that a linear trendline best represented (i.e. highest $R^{2}$ fit) their relationship.

Table 3 and Fig. 2 show the estimation of the values for the standardized coefficients of the parameters, significance levels and goodness-of-fit indices of the SEM. The model's overall fit proved to be good, as were the standardized loads, the indicators and their significance levels (all $t$ values above 1.96, $p<0.05$ ). Both the compound reliability and the extracted variance analysis surpassed the recommended limits of 0.70 and 0.50 , respectively [26]. Moreover, discriminate validity analysis did not uncover any correlated endogenous perspectives [27]. As expected, the implemented technology/system has a very significant influence on the user orientation perspective $(t=12.60, p<0.001)$. Moreover, the technology/system perspective impacts on every other perspective of the framework. Reinforcing the results of the previous study [22], one of the key outcomes of effective IT implementation, namely, strategic competitiveness is fairly evenly influenced by the three enabling perspectives. As per any commercial venture, the key requirement is quantitative benefits for the business/project. The results confirm that the primary direct influential impacts on the benefits perspective come from the operational $(t=4.01 ; p<0.001)$ and strategic competitiveness $(t=3.79 ; p<0.001)$ perspectives while both direct and indirect influences come from the technology/system perspective $(t=1.96 ; p<0.05)$. Surprisingly, the user orientation perspective did not have any significant influence on the operational perspective.

The results of the different indicators on the model's goodness-of-fit are good (NFI $=0.999, \mathrm{CFI}=1.000$, RMSEA $=0.000$, GFI $=0.999$, IFI $=1.006$ and AGFI $=0.994)$. The reader is referred to ITS [28] for a complete description of these goodness-of-ft measures and their respective threshold acceptance levels. This 
confirms that the equations that define the path model are representative of the sample. The remaining indices have values that are within the acceptable range. In short, these results validate the model formulated.

\section{(INSERT FIGURE 2)}

Fig. 2 Final path model

Table 3 Standardized estimated coefficients for the final path model

(INSERT TABLE 3)

\section{Model implementation: case studies}

Two large infrastructure projects where web-based collaboration platforms were being utilized by project staff were selected as case studies. The developed structural equations derived from the path model were used to predict the IT-induced benefits and strategic competitiveness on these projects. Actual performance scores were then compared against predicted values to reinforce the validity of the path model. The following two sections provide a brief description of the case study projects and evaluated IT tool. Additionally, the final section details the results of the comparative analysis study.

\subsection{Case studies profile}

It should be noted that only basic details of the case studies and their respective participants is provided due to confidentiality requirements. Two large infrastructure projects constructed in Australia were selected for the case studies. Both of these projects were procured through a build-own-operate-transfer agreement and were valued in excess of one billion US dollars. Moreover, both projects utilized the same web-based collaboration platform described in the next section. Other IT applications and/or tools used on the project were not evaluated in this case study. As previously mentioned, a representative sample of professional staff from different disciplines, were requested to participate in this IT performance evaluation exercise. It should be noted that the respondent samples obtained from the case studies were not intended to have the degree of 
rigour required for any complex statistical analysis. Their intended purpose was to reinforce the validity of the developed path model and associated equations. Therefore, only a small sample was required for Project $1(n=14)$ and Project $2(n=26)$.

\subsection{Evaluated IT tool}

The evaluated IT tool in these case studies was a web-based collaboration tool used for all project communication and the real-time management of all project documents and drawings. It supports the interactive design process within and between organizations and manages the work-flow between architects, engineers, consultants, subcontractors and the construction site. Documents are stored centrally in a secure data centre, so version control can be managed effectively and users can be certain that they are dealing with the latest document. The business case for the construction consortium implementing the web-based collaboration platform was numerous and included the following: reduction in paper copying costs; enhanced document control; increased audit capabilities; to name a few.

It should be noted that senior management supported the implementation of the web-based system. Utilizing the web-based information management system was deemed mandatory for all employees. The use of other methods of document exchange or email exchange was banned. Clauses were written into subcontractors and design consultants contracts stating that the system was the only recognised vehicle for document and drawing exchange. The IT tool was supported by dedicated IT training and support staff. Moreover, all the processes that are managed through the tool are mapped onto flow charts, documented and incorporated into the project quality manual. However, working against this commitment, was the relative immaturity of the system and the limited familiarity of its users. This was reflected by the relatively low 'actual' scores obtained for the two projects, particularly, in the technology/system and user orientation perspectives (see Table 4). 


\subsection{Prediction comparative analysis}

To reinforce the validity of the path model a comparative analysis between the collected actual mean scores for each perspective of the 'Construct IT' BSC and the predicted scores derived from the path standardized prediction equations was conducted. To achieve this, actual scores obtained from the case studies were converted to an equivalent $Z$ score (standardized value) on the original Australia-wide distribution. Single or combinations of $Z$ scores were utilized in the appropriate standardized equations to predict the $Z$ score, and ultimately the actual score, for endogenous perspectives. For example, for the developed strategic competitiveness perspective function (i.e. $Z_{S C}=0.29 Z_{T S}+0.25 Z_{U O}+0.33 Z_{O P}$ ), the $Z$ scores for each independent perspective in Project 1 were $Z_{T S}=-0.56, Z_{U O}=-0.21$, and $Z_{O P}=-0.75$. The calculated $Z_{S C}=$ 0.46 score equates to a predicted strategic competitiveness value of 3.48 , representing a difference of 0.05 or 1.46 per cent from the actual score (see Table 4). As expected, functions with only one dependent variable less accurately predicted the dependent variables i.e. $U O=f(T S)$ and $O P=f(T S)$. Table 4 details the extent of the difference between the actual project scores and the standardized predicted value. Figure 3 illustrates the linear standardized trend line for each paths respective structural equation (see Table 3 ) and the predicted actual values for Projects 1 and 2 .

In summary, the developed path model reasonably accurately represents the results obtained from the two case studies, especially for the outcome-focused perspectives (i.e. SC and BE). However, from the analysis it became evident that the actual results collected from the case studies were predominately slightly lower than those predicted. Moreover, Project 1 results were generally more accurately predicted. These two outcomes may be due to a number of causes. Firstly, due to the large contract value of the projects a high percentage of contract staff were mobilized who were mostly first-time users of the web-based collaboration tool, thus the distribution of scores was lower than the original sample. Secondly, the IT performance evaluation exercise was undertaken in the early stages of procurement for Project 2 and the later stages for Project 1, giving the latter respondents more time to familiarize themselves with the IT system, thus their mean scores were slightly higher. 
Table 4 Prediction comparative analysis

(INSERT TABLE 4)

(INSERT FIGURE 3)

Fig. 3 Standardized prediction value (Project 1 and 2)

(a) $\mathrm{UO}=f(\mathrm{TS})$; (b) $\mathrm{OP}=f(\mathrm{TS})$; (c) $\mathrm{SC}=f(\mathrm{TS}, \mathrm{UO}, \mathrm{OP})$; (d) $\mathrm{BE}=f(\mathrm{TS}, \mathrm{OP}, \mathrm{SC})$

\section{Concluding Remarks}

The empirical link between 'Construct IT' BSC perspectives was established utilizing structural equation modeling. Moreover, the validity of the developed path model was reinforced through IT benchmarking studies conducted on two mega infrastructure projects constructed in Australia, where innovative web-based collaboration systems were implemented. Specifically, findings suggest that the framework can be used as a tool for monitoring the IT-induced value creation process. Undoubtedly, the model provides evidence that firms which provide reliable IT systems that are well-supported and user-friendly will achieve higher ITinduced performance improvement in the operational, strategic competitiveness and benefits perspectives. Accordingly, construction businesses are encouraged to closely monitor indicators from the user orientation and technology/system perspectives. A slack in these indicators often signals retarding performance in the outcomes-based perspectives. In conclusion, it is hoped that this study will encourage construction firms to adopt the proposed framework to assist with the measurement and management of implemented IT projects. Last, but not least, it should be noted that the 'Construct IT' BSC framework should be regarded as a template only and needs to be carefully adapted to suit the individual needs of construction firms and the portfolio of IT tools and/or systems implemented. 


\section{References}

[1] S. Bowden, A. Dorr, T. Thorpe and C. Anumba, Mobile ICT support for construction process improvement, Automation in Construction 15 (2005) 664-676.

[2] A.N. Baldwin, A. Thorpe, and C. Carter, The use of electronic information exchange on construction alliance projects, Automation in Construction 8 (1999) 651-662.

[3] M. Hannus, A. Watson, B. Luiten, M. Deguine, G. Sauce and T. Van Rijn, ICT tools for improving the competitiveness of the LSE Industry, Journal of Engineering, Construction and Architectural Management 6 (1999) 30-37.

[4] Z.M. Deng, H. Li, C.M. Tam, Q.P. Shen and P.E.D. Love, An application of internet-based project management system, Automation in Construction 10 (2001) 239-246.

[5] C.H. Caldas and L. Soibelman, Automating hierarchical document classification for construction management information systems, Automation in Construction 12 (2003) 395- 406.

[6] V. Peansupap and D. Walker, Exploratory factors influencing information and communication technology diffusion and adoption within Australian construction organizations: a micro analysis, Construction Innovation 5 (2005) 135-157.

[7] D.H.T. Walker and K.D. Hampson, Procurement Strategies: A Relationship Based Approach (Blackwell Publishing, Oxford, 2003).

[8] K. Ruikar, C.J. Anumba and P.M. Carrillo, End-user perspectives on use of project extranets in construction organizations, Engineering, Construction and Architectural Management 12 (2005) 222235. 
[9] M. Betts, Strategic Management of IT in Construction (Blackwell Science, Oxford, 1999).

[10] F. Pena-Mora, S. Vadhavkar, E. Perkins and T. Weber, Information technology planning framework for large-scale projects, Journal of Computing in Civil Engineering, October (1999) 226-237.

[11] P.E.D. Love and Z. Irani, An exploratory study of information technology evaluation and benefits management practices of SMEs in the construction industry, Information \& Management 42 (2004) $227-242$.

[12] R.A. Stewart, S. Mohamed and R. Daet, Strategic implementation of IT/IS projects in construction: a case study. Automation in Construction 11 (2002) 681-694.

[13] P. Nitithamyong and M.J. Skibniewski, Web-based construction project management systems: how to make them successful? Automation in Construction 13 (2004) 491- 506.

[14] Z. Irani and P.E.D. Love, The propagation of technology management taxonomies for evaluating investments in information systems, Journal of Management Information Systems 17 (2001) 161-177.

[15] R.A. Stewart and S. Mohamed, Evaluating the value IT adds to the process of project information management in construction, Automation in Construction 12 (2003) 407-417.

[16] P.E.D. Love, Z. Irani and D.J. Edwards, Industry-centric benchmarking of information technology benefits, costs and risks for small-to-medium sized enterprises in construction, Automation in Construction 13 (2004) 507-524.

[17] B.L. Dos Santos, L. Sussman, Improving the return on IT investment: the productivity paradox, International Journal of Information Management 20 (2000) 429-440. 
[18] P.E.D. Love, Z. Irani, D.J. Edwards, Researching the investment of information technology in construction: an examination of evaluation practices, Automation in Construction 14 (2005) 569- 582.

[19] Y. Jung and G.E. Gibson, Planning for computer integrated construction, Journal of Computing in Civil Engineering 13 (1999) 217-225.

[20] J. Andresen, A. Baldwin, M. Betts, C. Carter, A. Hamilton, E. Stokes, and T. Thorpe, A framework for measuring IT innovation benefits, Electronic Journal of Information Technology in Construction (www.itcon.org) 5 (2000) 57-72.

[21] L. Marsh and R. Flanagan, Measuring the costs and benefits of information technology in construction, Engineering, Construction and Architectural Management 7 (2000) 423-435.

[22] R.A. Stewart and S. Mohamed Evaluating web-based project information management in construction: capturing the long-term value creation process, Automation in Construction 13 (2004) 469-479.

[23] R.A. Stewart, S. Mohamed and M. Marosszeky, An empirical investigation into the link between information technology implementation barriers and coping strategies in the Australian construction industry, Construction Innovation 4 (2004) 155-171.

[24] S. Mohamed and R.A. Stewart, An empirical investigation of users' perceptions of web-based communication on a construction project, Automation in Construction 12 (2003) 43-53.

[25] M. Zain, R.C. Rose, I. Abdullah, and M. Masrom, The relationship between information technology acceptance and organizational agility in Malaysia, Information \& Management 42 (2005) 829-839. 
[26] J.F. Hair, R.E. Anderson, R.L. Tatham and W.C. Black, Multivariate Data Analysis (Prentice-Hall, New Jersey, 1998).

[27] J.C. Anderson and D.W. Gerbing, Structural equation modelling in practice: a review and recommended two-step approach, Psychological Bulletin 103 (1988) 411-423.

[28] ITS, Structural Equation Modeling using AMOS: An Introduction (The University of Texas at Austin, Texas, USA, 2001). 
Table 1

Mean value and standard deviation for indicators [22]

Table 2

Correlation between perspectives

Table 3

Standardized estimated coefficients for the final path model

Table 4

Prediction comparative analysis

Fig. 1 'Construct IT’ BSC [15]

Fig. 2 Final path model

Fig. 3 Standardized prediction value (Project 1 and 2)

(a) $\mathrm{UO}=f(\mathrm{TS})$; (b) $\mathrm{OP}=f(\mathrm{TS})$; (c) $\mathrm{SC}=f(\mathrm{TS}, \mathrm{UO}, \mathrm{OP})$; (d) $\mathrm{BE}=f(\mathrm{TS}, \mathrm{OP}, \mathrm{SC})$ 
Table 1

Mean value and standard deviation for indicators [22]

\begin{tabular}{|c|c|c|c|}
\hline Code & Indicator Description & Mean & Std. dev. \\
\hline \multicolumn{2}{|c|}{ Operational Perspective (OP) } & 3.95 & 0.72 \\
\hline OP1 & Processing of progress claims & 4.05 & 0.91 \\
\hline OP2 & Contract administration & 4.00 & 0.82 \\
\hline OP3 & Coordination and communication & 4.15 & 0.93 \\
\hline OP4 & Reporting and feedback & 3.96 & 0.92 \\
\hline OP5 & Responding to requests & 3.93 & 0.89 \\
\hline OP6 & Optimizing staff utilization & 3.62 & 0.88 \\
\hline \multicolumn{2}{|r|}{ Benefits Perspective (BE) } & 3.92 & 0.79 \\
\hline BE1 & Realizing time savings (data processing, responding, etc.) & 3.99 & 0.95 \\
\hline $\mathrm{BE} 2$ & Reducing multiple handling of documents & 3.90 & 0.92 \\
\hline $\mathrm{BE} 3$ & Improving document quality & 3.93 & 0.95 \\
\hline BE4 & Realizing cost savings (due to less re-work, traveling, etc.) & 3.85 & 0.98 \\
\hline \multicolumn{2}{|c|}{ Strategic Competitiveness Perspective (SC) } & 3.81 & 0.72 \\
\hline $\mathrm{SC} 1$ & Improve client satisfaction & 3.85 & 0.82 \\
\hline $\mathrm{SC} 2$ & Enhance organizational competitiveness & 3.89 & 0.89 \\
\hline $\mathrm{SC} 3$ & Enhance organizational image & 3.95 & 0.87 \\
\hline $\mathrm{SC} 4$ & Forge project alliances through electronic means & 3.83 & 0.83 \\
\hline SC5 & Attract more sophisticated clients & 3.52 & 0.86 \\
\hline \multicolumn{2}{|c|}{ Technology/System Perspective (TS) } & 3.55 & 0.66 \\
\hline TS1 & Reliability & 3.52 & 0.82 \\
\hline TS2 & Appropriateness for application/function & 3.57 & 0.79 \\
\hline TS3 & Quality of output & 3.67 & 0.86 \\
\hline TS4 & Security & 3.62 & 0.84 \\
\hline TS5 & Suitability for site conditions & 3.35 & 0.92 \\
\hline \multicolumn{2}{|c|}{ User Orientation Perspective (UO) } & 3.31 & 0.80 \\
\hline UO1 & The level and frequency of training provided & 2.89 & 1.05 \\
\hline UO2 & The level and frequency of supported provided & 3.17 & 1.04 \\
\hline UO3 & The level and frequency of IT utilization & 3.55 & 0.93 \\
\hline UO4 & The IT applications/tools adopted by your organization & 3.57 & 0.83 \\
\hline UO5 & The user friendliness of the IT applications/tools adopted & 3.39 & 0.87 \\
\hline
\end{tabular}


Table 2

Correlation between perspectives

\begin{tabular}{llllllll}
\hline Perspective & Mean & S.D. & OP & BE & SC & TS & UO \\
\hline Operational (OP) & 3.95 & 0.72 & 1 & & & & \\
Benefits (BE) & 3.92 & 0.79 & $0.74^{* * *}$ & 1 & & & \\
Strategic Competitiveness (SC) & 3.81 & 0.72 & $0.66^{* * *}$ & $0.74^{* * *}$ & 1 & & \\
Technology/System (TS) & 3.55 & 0.66 & $0.67^{* * *}$ & $0.70^{* * *}$ & $0.71^{* * *}$ & 1 & \\
User Orientation (UO) & 3.31 & 0.80 & $0.56^{* * *}$ & $0.59^{* * *}$ & $0.67^{* * *}$ & $0.81^{* * *}$ & 1 \\
\hline$n=82 ; * p<0.05 ; * * p<0.01 ; * * * p<0.001$ & & & & & & & \\
\hline
\end{tabular}


Table 3

Standardized estimated coefficients for the final path model

\begin{tabular}{lllll}
\hline Paths & Structural equations & Coefficient & $t$ & $R^{2}$ \\
\hline $\mathrm{TS} \rightarrow \mathrm{UO}$ & $Z_{U O}=0.81\left(Z_{T S}\right)$ & $\gamma=0.81$ & $12.60^{* * *}$ & 0.66 \\
& & & & \\
$\mathrm{TS} \rightarrow \mathrm{OP}$ & $Z_{O P}=0.67\left(Z_{T S}\right)$ & $\gamma=0.67$ & $8.11^{* * *}$ & 0.45 \\
& & & \\
$\mathrm{TS} \rightarrow \mathrm{SC}$ & $Z_{S C}=0.29\left(Z_{T S}\right)+0.25\left(Z_{U O}\right)+0.33\left(Z_{O P}\right)$ & $\gamma=0.29$ & $2.09^{*}$ & 0.59 \\
$\mathrm{UO} \rightarrow \mathrm{SC}$ & & $\beta=0.25$ & $2.05^{*}$ & \\
$\mathrm{OP} \rightarrow \mathrm{SC}$ & & $\beta=0.33$ & $3.45^{* * *}$ & \\
& & & \\
$\mathrm{TS} \rightarrow \mathrm{BE}$ & $\mathrm{Z}_{\mathrm{BE}}=0.19\left(Z_{T S}\right)+0.37\left(Z_{O P}\right)+0.37\left(Z_{S C}\right)$ & $\gamma=0.19$ & $1.96^{*}$ & 0.67 \\
$\mathrm{OP} \rightarrow \mathrm{BE}$ & & $\beta=0.37$ & $4.01^{* * *}$ & \\
$\mathrm{SC} \rightarrow \mathrm{BE}$ & & $\beta=0.37$ & $3.79^{* * *}$ & \\
\hline $\mathrm{R}$ & & &
\end{tabular}

Relative chi-square $\left(\chi^{2} / \mathrm{df}\right)=0.081$; Goodness of fit $(\mathrm{GFI})=0.999$; Adjusted goodness of fit $(\mathrm{AGFI})=0.994$;

Comparative fit index $(\mathrm{CFI})=1.000$; Normed fit index $(\mathrm{NFI})=0.999$; Incremental fit index $(\mathrm{IFI})=1.006$; Root mean square error of approximation (RMSEA) $=0.000 ;{ }^{*} p<0.05 ; * * p<0.01 ; * * *<0.001$ 
Table 4

Prediction comparative analysis

\begin{tabular}{lllllllll}
\hline Prediction Equation & \multicolumn{2}{l}{ Project $1(n=14)$} & \multicolumn{5}{c}{ Project $2(n=26)$} \\
& Predicted & Actual & Diff. & Per cent & Predicted & Actual & Diff. & Per cent \\
\hline TS & $*$ & 3.18 & $*$ & $*$ & $*$ & 2.97 & $*$ & $*$ \\
$\mathrm{UO}=f(\mathrm{TS})$ & 2.95 & 3.14 & -0.19 & -6.05 & 2.74 & 3.13 & -0.39 & -12.46 \\
$\mathrm{OP}=f(\mathrm{TS})$ & 3.68 & 3.41 & 0.27 & 7.92 & 3.53 & 3.26 & 0.27 & 8.28 \\
$\mathrm{SC}=f(\mathrm{TS}, \mathrm{UO}, \mathrm{SC})$ & 3.48 & 3.43 & 0.05 & 1.46 & 3.36 & 3.40 & -0.04 & -1.18 \\
$\mathrm{BE}=f(\mathrm{TS}, \mathrm{OP}, \mathrm{SC})$ & 3.46 & 3.44 & 0.02 & 0.58 & 3.34 & 3.17 & 0.17 & 5.36 \\
\hline
\end{tabular}

* Exogenous perspective 


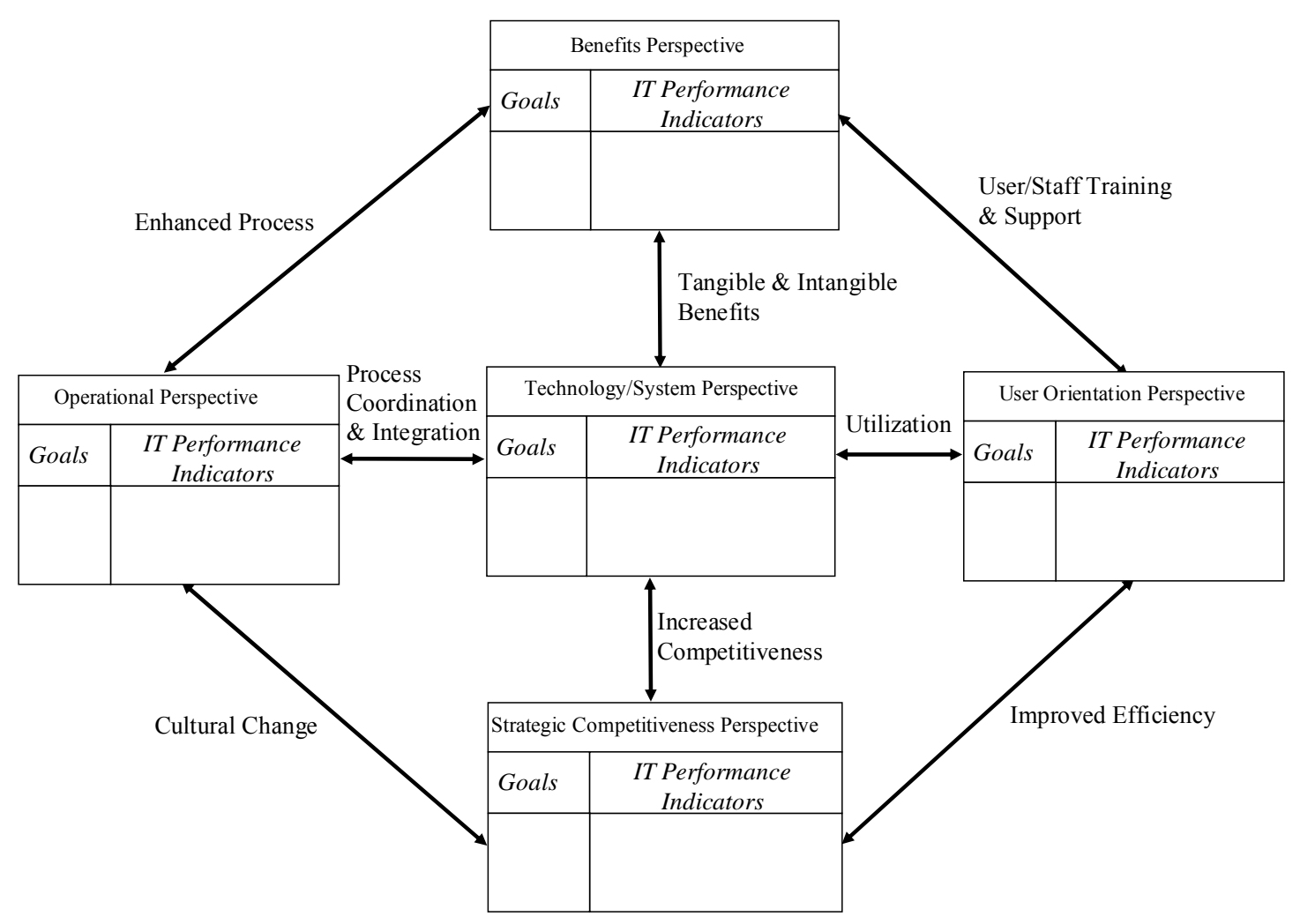

Fig. 1 'Construct IT' BSC [15] 


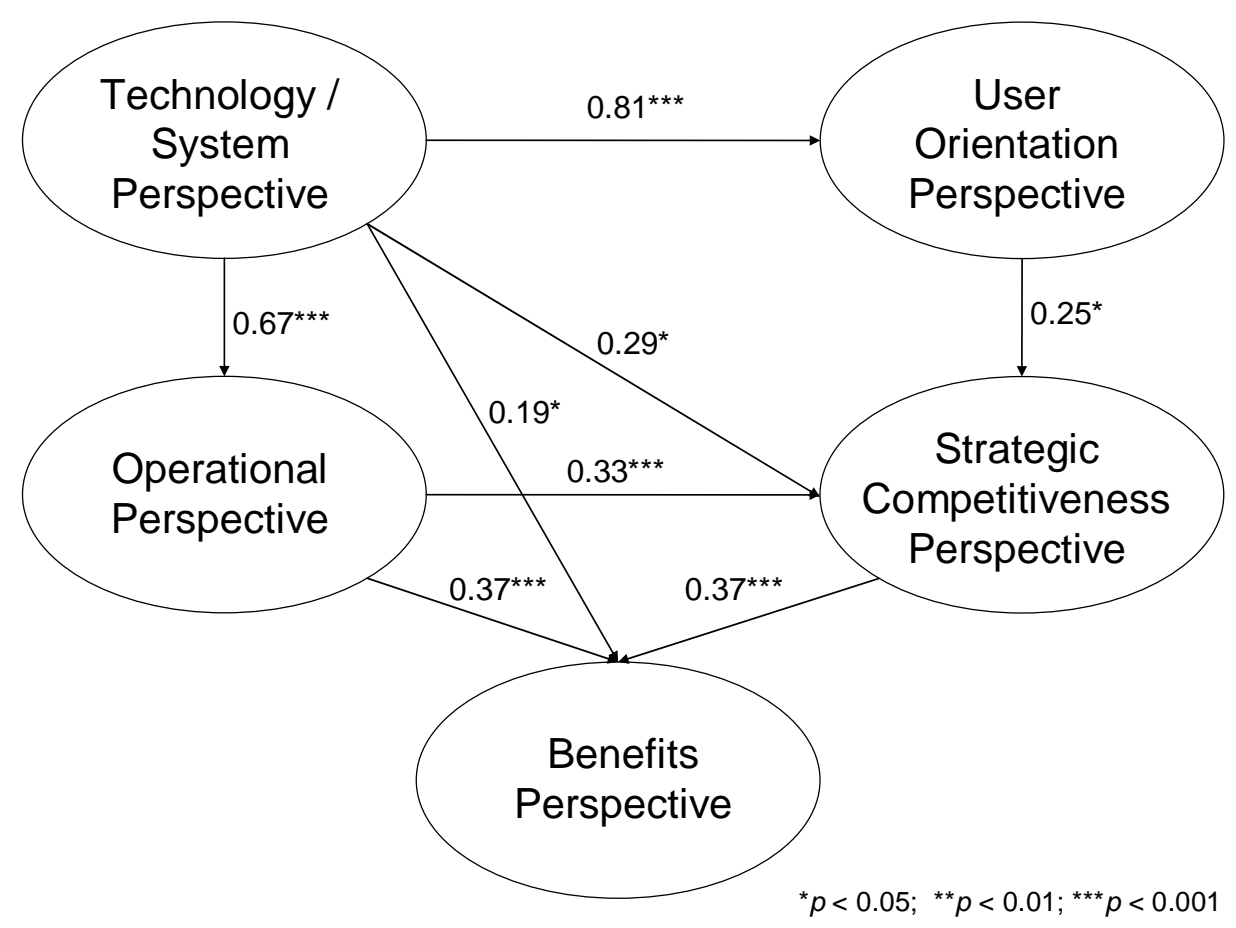

Fig. 2 Final path model 

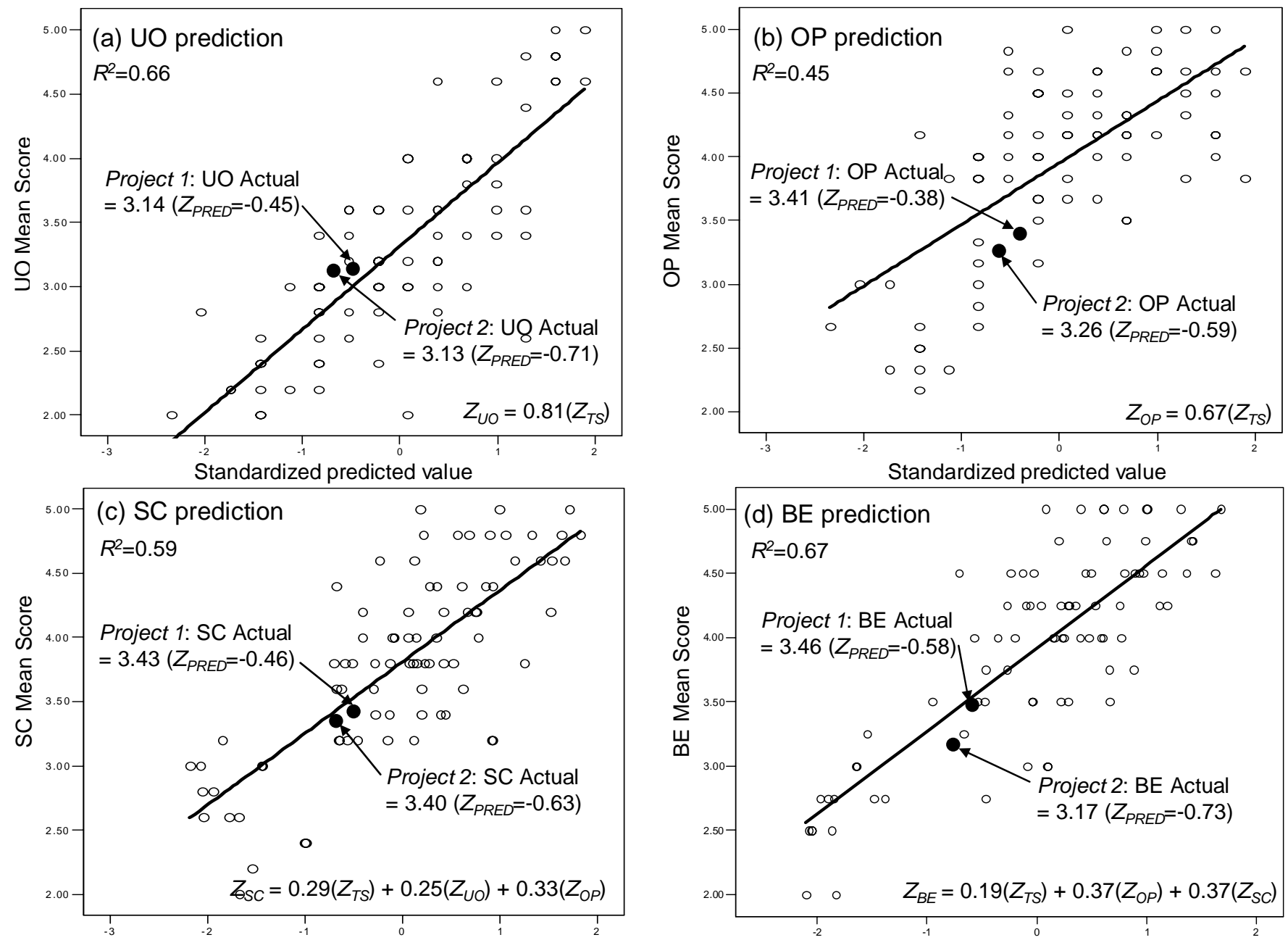

Fig. 3 Standardized prediction value (Project 1 and 2)

(a) $\mathrm{UO}=f(\mathrm{TS})$; (b) $\mathrm{OP}=f(\mathrm{TS})$; (c) $\mathrm{SC}=f(\mathrm{TS}, \mathrm{UO}, \mathrm{OP})$; (d) $\mathrm{BE}=f(\mathrm{TS}, \mathrm{OP}, \mathrm{SC})$ 